\title{
Numerical study on the electrical performance of photovoltaic panel with passive cooling of natural ventilation
}

\author{
Hongbing Chen", Xilin Chen, Sizhuo Li, Hanwan Ding \\ School of Environment and Energy Engineering, Beijing University of Civil Engineering and Architecture, Beijing 100044 China
}

\begin{abstract}
Many researchers employed air or water for the active cooling of PV to achieve higher electrical efficiency, but additional energy consumption for fan or water pump may reduce the net power output. Therefore, this paper provided a study on the electrical performance of PV panel with passive fin cooling of natural ventilation with the consideration of the effect of PV panel tilt angle, solar radiation, air temperature and wind velocity as well as fin size on PV energy performance. The study showed that there existed a PV tilt angle resulting in the minimum electrical efficiency and the maximum power output. Higher intensity of solar radiation led to lower PV electrical efficiency and the efficiency dropped to the minimum around 11:40 during the day time in Beijing. The PV electrical efficiency decreased in linear with the increasing air temperature, but it increased with the increasing wind velocity. The effect of fin height on the electrical efficiency seemed to be very slight. The average electrical efficiency of PV panel with fins was $0.27 \sim 1.14 \%$ higher than that of PV panel without fins under various conditions in this study.
\end{abstract}

Keywords:Passive cooling, natural ventilation, PV panel, electrical performance

\section{Introduction}

With the rapid economic development, energy demand and consumption had been sharply increasing in the past two decades. Fossil fuel reserve has been proven to be very limited, therefore, the development and utilization of renewable energy becomes more and more important. Solar energy, as a green and renewable energy, has been widely used for solar-electricity generation with photovoltaic (PV) panel in recent years. In 2012, the global PV production was $36 \mathrm{GW}$ and $63.9 \%$ of them were produced in China. The electrical efficiency of commercial PV products was mostly less than 20\%. Many studies [1], [2] found that PV cell/working temperature had a great impact on the solar-to-electricity conversion efficiency (PV electrical efficiency), and the higher PV cell temperature was, the lower the electrical efficiency would be. Many studies [3]-[7] of active PV cooling, employing air, water or refrigerant to extract heat from PV and combining PV panel with heat storage or heat pump for PV/thermal (PV/T) system, have been carried out to improve PV energy performance. But those systems consumed extra energy to drive the cooling fluid, and the improvement of electricity production by active cooling was very slight compared with the extra energy consumption for fan, water pump and compressor. Passive cooling with no extra energy consumption could be an option to improve PV electrical performance, even the cooling effect and energy improvement was not as good as expected. Therefore, this paper provided a study on the electrical performance of PV panel with passive fin cooling of natural ventilation.

\section{Numerical Models}

Zondag et al. [8] built four numerical models for the simulation of PV/T collector: a 3-D dynamical model and three steady state models that are 3-D, 2-D and 1-D. The study showed that the 1-D steady

\footnotetext{
* Manuscript received May 13, 2014; revised July 26, 2014.

Corresponding author: Hongbing Chen; Tel.: +86-10-6832-2517; E-mail address: chenhongbing@ bucea.edu.cn

doi: $10.12720 /$ sgce.3.4.395-400
} 
state model performed almost as good as the others. Therefore, for this work, the 1-D steady state model was used for the simulation based on the following assumptions:

- The temperature at each layer was well distributed and the geometrical center was selected to be the representive node.

- The contact resistance between each layer was neglected.

- Based on the energy balance analysis of each layer, mathematic models were developed for the numerical simulations of PV energy performance.

The heat balance at the PV panel was given by

$$
0=I(\beta \tau)_{c} f_{c} A_{p}+I(\beta \tau)_{p}\left(1-f_{c}\right) A_{p}-E+h_{p-m}\left(T_{m}-T_{p}\right) A_{p}+h_{p-a}\left(T_{a}-T_{p}\right) A_{p}+h_{p-s k y}\left(T_{s k y}-T_{p}\right) A_{p}
$$

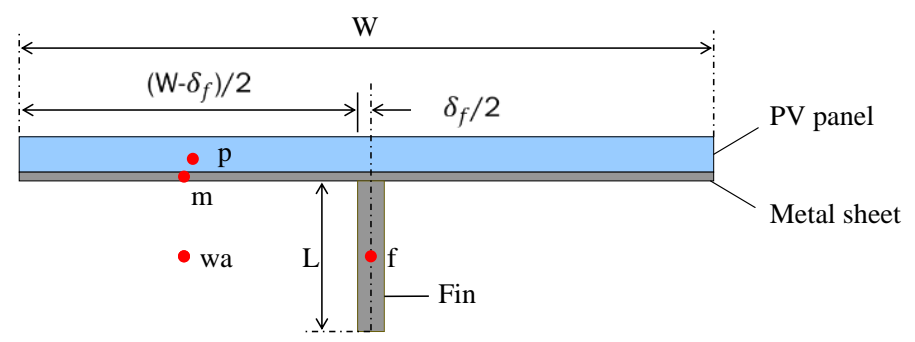

Fig. 1. Cross-sectional view of part PV panel with cooling fin.

where $I$ was solar radiation; $(\beta \tau)_{c}$ and $(\beta \tau)_{p}$ were the effective absorptances of the solar cells "c" and PV base plate respectively; $f_{c}$ was the ratio of cell area to PV panel area; $A_{p}$ was the area of PV panel " $p$ "; $E$ was the electricity generation; $h_{p-m}$ was the heat transfer coefficient between " $p$ " and the metal sheet " $m$ "; $h_{p-a}$ was the convective heat transfer coefficient between " $p$ " and the surrounding air " $a$ "; $h_{p-s k y}$ was the radiative heat transfer coefficient between " $p$ " and the sky; $T_{m}, T_{p}, T_{a}$ and $T_{s k y}$ were the temperature of " $m$ ", " $p$ ", " $a$ " and the sky respectively.

The electricity generation $(\mathrm{W})$ was given by:

$$
E=\eta_{c} f_{c}(\beta \tau)_{c} I A_{p}
$$

where $\eta_{c}$ was the temperature-dependent electrical efficiency of "c".

$$
\eta_{c}=\eta_{r c}\left[1-\beta\left(T_{p}-T_{r c}\right)\right]
$$

where $\eta_{r c}$ was the reference electrical efficiency at the reference operating temperature $T_{r c} ; \beta$ was the temperature coefficient [9].

$$
h_{p-m}=\frac{1}{R_{p-m}}
$$

$R_{p-m}$ was the thermal contact resistance between " $\mathrm{p}$ " and " $\mathrm{m}$ " $\left(0.04 \mathrm{~m}^{2} \cdot \mathrm{K} / \mathrm{W}\right)$.

According to Duffie and Beckman [9],

$$
h_{p-a}=2.8+3.0 \times u_{\text {wind }}
$$

where $u_{\text {wind }}$ was the wind velocity.

$$
h_{p-s k y}=\varepsilon_{p} \sigma\left(T_{p}^{2}+T_{s k y}^{2}\right)\left(T_{p}+T_{s k y}\right)
$$

where $\varepsilon_{p}$ was the emittance of " $p$ "; $\sigma$ was the Stefan-Boltzmann constant. 


$$
T_{s k y}=0.0552 \times T_{a}^{1.5}
$$

The heat balance at the metal sheet was given by:

$$
0=h_{p-a}\left(T_{p}-T_{m}\right) A_{p-m}+h_{m-f}\left(T_{f}-T_{m}\right) A_{m-f}+h_{m-w a}\left(T_{w a}-T_{m}\right) A_{m-w a}
$$

where $A_{p-m}$ was the contact area between " $p$ " and " $m$ "; $A_{m-f}$ was the contact area between " $m$ " and the fins " $f$ "; $A_{m-w a}$ was the contact area between "m" and the warm air " $w a " ; h_{m-f}$ was the conductive heat transfer coefficient between " $m$ " and " $f$ "; $h_{m-w a}$ was the convective heat transfer coefficient between "m" and "wa"; $T_{f}$ and $T_{w a}$ were the temperature of " $f$ " and "wa" respectively.

$$
\begin{aligned}
& h_{m-f}=\frac{1}{\frac{x_{m} A_{m-f}}{2 k_{m} \theta_{m} L}+\frac{y_{f} A_{m-f}}{k_{f} \theta_{f} L}} \\
& x_{m}=W / 4 \\
& y_{f}=L / 2
\end{aligned}
$$

where $k_{m}$ was the thermal conductivity of "m" $(200 \mathrm{~W} /(\mathrm{m} \cdot \mathrm{K})) ; \theta_{m}$ was the thickness of "m" $(2 \mathrm{~mm}) ; L$ was the height of " $f$ " $(80 \mathrm{~mm}) ; k_{f}$ was the thermal conductivity of " $\mathrm{f}$ " $(210 \mathrm{~W} /(\mathrm{m} \cdot \mathrm{K})) ; \theta_{f}$ was the thickness of " $f$ " $(2 \mathrm{~mm})$; W was the width of " $p$ " (10 mm).

$$
h_{m-w a}=\frac{2 k_{m} h_{p-a}}{2 k_{m}+\theta_{m} h_{p-a}}
$$

The heat balance at the fin was given by:

$$
\left.\left.0=h_{m-f} T_{f_{p}}-T_{f} A\right)_{n-f}+h_{f-w a} T_{(a a}-T_{f} A\right)_{f-w a}
$$

where $h_{f-w a}$ was the convective heat transfer coefficient between "f" and "wa" and was given by

$$
h_{f-w a}=\frac{2 k_{f} h_{p-a}}{\delta_{m} h_{p-a}+2 k_{f}}
$$

The heat balance for the warm air between the fins was given by:

$$
0=h_{m-w a}\left(T_{m}-T_{w a}\right) A_{m-w a}+h_{f-w a}\left(T_{f}-T_{w a}\right) A_{f-w a}+m_{w a} c\left(T_{a}-T_{w a}\right)
$$

where $m_{w a}$ was the mass flow of " $w a$ "; $c$ was the specific heat capacity of air.

The location of Beijing was selected for study in this paper. To simplify the calculation and analysis, the time point, 12:00 on October 15th, was employed for numerical simulation. The solar radiation on tilt front surface of PV panel was given by [10]

$$
I=I_{b}\left(\begin{array}{l}
\cos S \cdot \sin \phi \cdot \sin \delta+\cos S \cdot \cos \phi \cdot \cos \delta \cdot \cos \omega+\sin S \cdot \sin \gamma \cdot \cos \delta \cdot \sin \omega \\
+\sin S \cdot \sin \phi \cdot \cos \delta \cdot \cos \omega \cdot \cos \gamma-\sin S \cdot \cos \gamma \cdot \sin \delta \cdot \cos \phi
\end{array}\right)+I_{d}\left(\cos \frac{s}{2}\right)^{2}
$$

where $I_{d}$ was the diffuse radiation on horizontal surface; $I_{b}$ was the direct radiation on horizontal surface; $S$ was the angle between the inclined plane and the horizontal plane $\left(30^{\circ}\right) ; \phi$ was the geographical latitude $\left(39.80^{\circ}\right.$ in Beijing); $\delta$ was the solar latitude $(-9.60)$; $\omega$ was hour angle $\left(0^{\circ}\right.$ at $\left.12: 00\right) ; \gamma$ was the azimuth angle $\left(15^{\circ}\right) ; \alpha_{s}$ was the solar elevation.

$$
I_{d}=C_{1}\left(\sin \alpha_{s}\right)^{c_{2}}
$$




$$
\begin{aligned}
& \delta=23.45 \sin \left(\frac{2 \pi d}{365}\right) \\
& \sin \alpha_{s}=\sin \phi \cdot \sin \delta+\cos \phi \cdot \cos \delta \cdot \cos \omega
\end{aligned}
$$

\section{Result and Analysis}

\subsection{Effect of PV panel inclination on the electrical efficiency}

Fig. 2 showed the variation of PV electrical efficiency under different tilt angle of PV panel. It can be seen from Fig. 2 that the electrical efficiency dec reased to the lowest point and then increased slightly with the increasing PV panel tilt angle. For PV panel with fins, the electrical efficiency was $14.7 \%$ responding to the tilt angle of $20^{\circ}$. It decreased with the increasing tilt angle and reached the minimum of $14.6 \%$ at the tilt angle of $45^{\circ}$. After that, the electrical efficiency turned to increase and reached $14.63 \%$ as the tilt angle increased to $60^{\circ}$. The average electrical efficiency was $14.6 \%$. For PV panel without fins, the electrical efficiency was $14.5 \%$ responding to the tilt angle of $20^{\circ}$. It decreased with the increasing tilt angle and reached the minimum of $14.3 \%$ at the tilt angle of $45^{\circ}$. After that, the electrical efficiency turned to increase and reached $14.4 \%$ as the tilt angle increased to $60^{\circ}$. The average electrical efficiency was $14.4 \%$. It can be concluded from Fig. 2 that the PV cooling fins led to an average efficiency increase by $0.27 \%$ in this case.

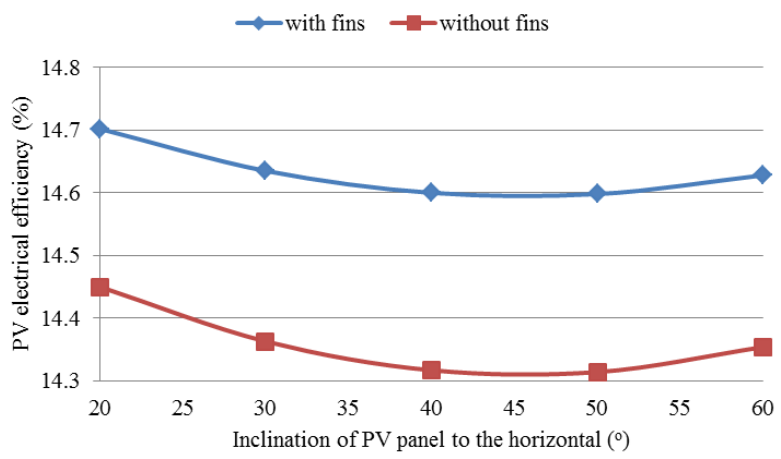

Fig. 2. Variation of electrical efficiency with PV panel tilt angle.

\subsection{Variation of electrical efficiency during the day time}

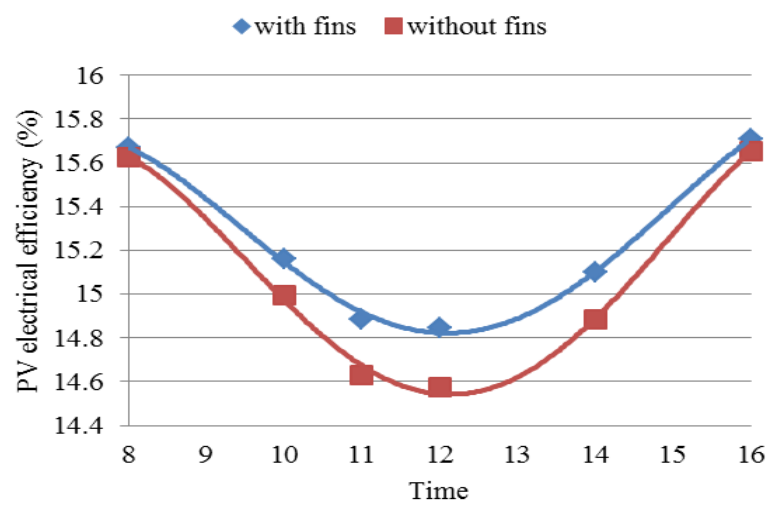

Fig. 3. Variation of electrical efficiency during the day time.

Fig. 3 showed the variation of PV electrical efficiency during the day time. It can be seen from Fig. 4 that the PV electrical efficiency decreased to the minimum before noon and then increased in the afternoon. For PV panel with fins, the electrical efficiency reduced from 15.7\% at 8:00 to $14.9 \%$ at 12:00, 
while it increased to $15.7 \%$ at $16: 00$. It reached the minimum of $14.8 \%$ around 11:40. The average electrical efficiency was $15.2 \%$. For PV panel without fins, the efficiency decreased from $15.6 \%$ at 8:00 to $14.6 \%$ at 12:00, while it increased to $15.7 \%$ at 16:00. At about 11:40, it reached the minimum of $14.6 \%$. The average electrical efficiency was $15.1 \%, 0.17 \%$ lower than that of PV with fins relatively.

\subsection{Effect of air temperature on the electrical efficiency}

Fig. 4 showed the variation of PV electrical efficiency under different air temperature. It can be seen from Fig. 4 that the efficiency decreased in linear with the increasing air temperature. As the air temperature increased from $269.15 \mathrm{~K}$ to $299.15 \mathrm{~K}$, the electrical efficiency decreased from $16.0 \%$ to $14.0 \%$ for PV panel with fins, while from $15.7 \%$ to $13.7 \%$ for PV panel without fins. Every $10 \mathrm{~K}$ air temperature increase led to an electrical efficiency decrease by $0.7 \%$. The average electrical efficiency of PV panel with fins was $0.28 \%$ higher than that of PV panel without fins.

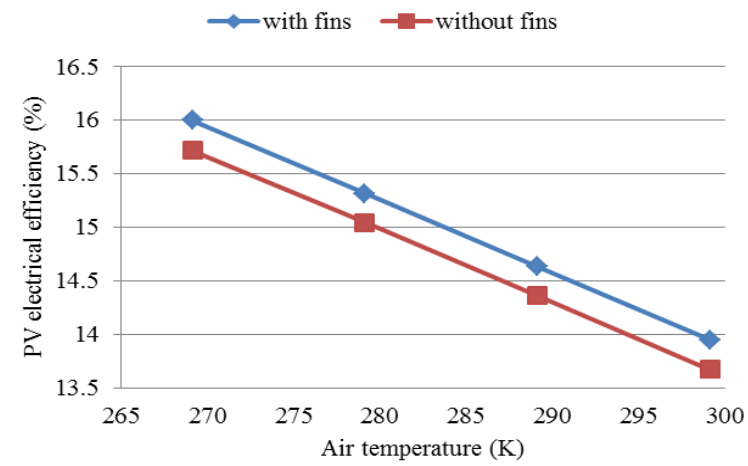

Fig. 4. Variation of electrical efficiency with air temperature.

\subsection{Effect of $P V$ panel inclination on electrical efficiency}

Fig. 5 showed the variation of PV electrical efficiency under different wind velocity. Higher wind velocity led to better fin cooling and consequently better PV electrical performance. The electrical efficiencies were $14.6 \%$ and $14.4 \%$ for PV panel with and without fins respectively at the wind velocity of $3 \mathrm{~m} / \mathrm{s}$. As the wind velocity increased to $6 \mathrm{~m} / \mathrm{s}$, the efficiencies increased to $14.9 \%$ and $14.8 \%$ respectively. With every $1 \mathrm{~m} / \mathrm{s}$ increase of wind velocity, the efficiency increased by $0.08 \%$ and $0.14 \%$, respectively.

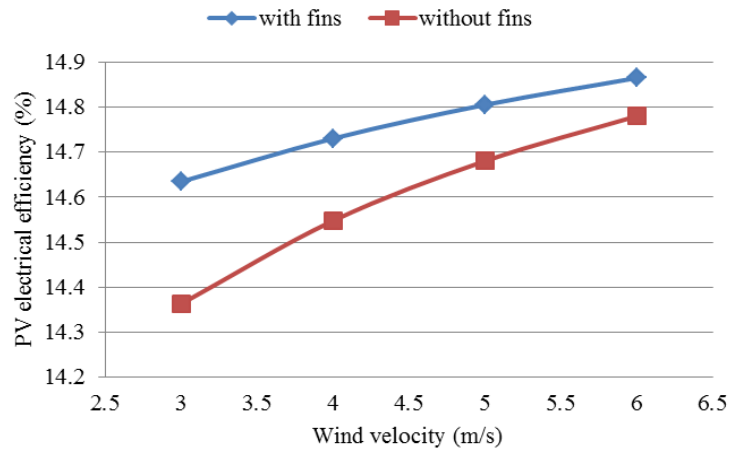

Fig. 5. Variation of electrical efficiency with wind velocity.

\section{Conclusions}

The paper presented a numerical study on the electrical performance of PV panel with passive cooling of natural ventilation. Numerical models were developed to investigate the effect of PV panel tilt angle, solar radiation, air temperature and wind velocity as well as fin size on the electrical efficiency and power 
output. The study could be concluded that:

1) As the PV panel tilt angle increased, the electrical efficiency dropped to the minimum at the tilt angle of $45^{\circ}$ and then rose slightly. The average electrical efficiency of PV panel with fins was $0.27 \%$ higher than that of PV panel without fins.

2) Higher intensity of solar radiation led to lower PV electrical efficiency. During the day time, the efficiency dropped to the minimum at around 11:40 and then went up for PV panels with and without fins. The average electrical efficiency of PV panel with fins was $1.13 \%$ higher than that of PV panel without fins.

3) The PV electrical efficiency decreased in linear with the increasing air temperature. Every $10 \mathrm{~K}$ decrease in air temperature led to the increase of electrical efficiency by $0.68 \%$ for PV panels with and without fins. The average electrical efficiency of PV panel with fins was $0.28 \%$ higher than that of PV panel without fins.

4) Higher wind velocity led to better PV cooling effect as well as better electrical performance. Every 1 $\mathrm{m} / \mathrm{s}$ increase in wind velocity led to the increase of electrical efficiency by $0.08 \%$ and $0.14 \%$ for PV panels with and without fins, respectively. The average electrical efficiency of PV panel with fins was $1.14 \%$ higher than that of PV panel without fins.

\section{Acknowledgements}

The work of this paper is fully supported by Funding Project for New Star of Scientific and Technical Research of Beijing (2011029), The Importation and Development of High-Caliber Talents Project of Beijing Municipal Institutions (CIT\&TCD201304067) and Beijing Municipal Key Lab of HVAC.

\section{References}

[1] Skoplaki E, Palyvos JA. On the temperature dependence of photovoltaic module electrical performance: A review of efficiency/power correlations. Solar Energy, 2009; 83(5):614-624.

[2] Assoa YB, Menezo C, Fraisse G, Yezou R, Brau J. Study of a new concept of photovoltaic-thermal hybrid collector. Solar Energy, 2007; 81(9):1132-1143.

[3] Tonui JK, Tripanagnostopoulos Y. Improved PV/T solar collectors with heat extraction by forced or natural air circulation. Renewable Energy, 2007; 32(4):623-637.

[4] Kumar R, Rosen MA. Performance evaluation of a double pass PV/T solar air heater with and without fins. Applied Thermal Engineering, 2011; 31(8-9):1402-1410.

[5] Dubey S, Tiwari GN. Thermal modeling of a combined system of photovoltaic thermal (PV/T) solar water heater. Solar Energy, 2008; 82(7):602-612.

[6] He W, Zhang Y, Ji J. Comparative experiment study on photovoltaic and thermal solar system under natural circulation of water. Applied Thermal Engineering, 2011; 31(16):3369-3376.

[7] Tiwari A, Sodha MS. Performance evaluation of hybrid PV/thermal water/air heating system: A parametric study. Renewable Energy, 2006; 31(15):2460-2474.

[8] Zondag HA, de Vries DW, van Helden WGJ, et al. The yield of different combined PV-thermal collector designs. Solar Energy, 2003; 74(3):253-269.

[9] Duffie JA, Beckman WA. Solar Engineering of Thermal Processes. 3rd ed., New York: Wiley; 2006.

[10] Fang R, Cheng X. The Solar Energy Application Technology. Beijing: China Agricultural Machinery Press; 1985. 